\title{
Short Synthesis and Anti-Rhinoviral Activity of Imidazo[1,2-a]Pyridines: The Effect of Acyl Groups at 3-Position
}

\author{
Chafiq Hamdouchi, ${ }^{* a}$ Jesús Ezquerra, ${ }^{a}$ Juan A. Vega ${ }^{b}$ Juan J. Vaquero, ${ }^{* b}$ Julio Alvarez-Builla ${ }^{\mathrm{b}}$ \\ and Beverly A. Heinz ${ }^{\mathrm{c}}$ \\ ${ }^{a}$ Centro de Investigación Lilly S. A., Avenida de la Industria 30, 28108-Alcobendas (Madrid)-Spain \\ ${ }^{b}$ Departamento de Química Orgánica, Universidad de Alcalá, 28871-Alcalá de Henares ( Madrid)-Spain \\ 'Infectious Diseases Research, Lilly Research Laboratories, Indianapolis, IN 46285
}

Received 9 December 1998; accepted 6 April 1999

\begin{abstract}
Various 2-amino-3-acyl-6-[(E)-1-phenyl-2- $N$-methylcarbamoylvinyl]-imidazo[1,2-a]pyridines, structurally related to Enviroxime were prepared to determine the effect of acyl groups on the antirhinoviral activity. A short and efficient means for the construction of the imidazo nucleus as well as biological evaluation of the final compounds are disclosed. () 1999 Elsevier Science Ltd. All rights reserved.
\end{abstract}

Enviroxime ${ }^{1}$ and related benzimidazoles ${ }^{2,3}$ showed potent broad spectrum antiviral activity against a range of both rhinoviruses and enteroviruses. Noncytotoxic concentrations of Enviroxime are associated with complete inhibition of replication of 81 rhinovirus serotypes. However, studies of oral Enviroxime showed low levels in blood and nasal secretions and an unacceptably high frequency of nausea and vomiting. ${ }^{4}$ Thus, despite its potent in vitro anti-rhinovirus activity, significant therapeutic benefit was not found with either oral or intranasal administration, and Enviroxime clinical studies were terminated. Despite this failure, considerable efforts are still devoted to the benzimidazole family with the aim of finding an antirhinoviral analogue with improved oral plasma levels and better safety profile. ${ }^{5}$<smiles></smiles>

Enviroxime<smiles></smiles>

Figure 1

As part of our ongoing program directed to the identification of non-benzimidazole structurally related analogues to Enviroxime, we have recently reported that 2-amino-6-[(E)-1-phenyl-2- $N$ methylcarbamoylvinyl]-imidazo[1,2-a]pyridines ${ }^{6}$ can maintain the anti-rhinoviral activity found in benzimidazoles. In this new family the substitution at 3-position was a key element for activity and both isopropyl sulfenyl and aromatic rings were well tolerated.

In a recent report, Spitzer $e t a l^{2,3}$ provided strong evidence for internal hydrogen bonding between the amine hydrogen and the sulfonyl oxygen which could account for the high potency exhibited by the Enviroxime. Acyl groups that would be expected to participate in the internal hydrogen-bond in an

E-mail: hamdouchi_chafiq@lilly.com Fax: (3491) 663-3411 
analogous way as sulfonyl groups, were not investigated in the benzimidazole series because of their chemical instability. Herein we wish to report that the structurally related analogues, imidazo[1,2-a] pyridines 1a-d, may overcome the SAR limitation of benzimidazoles in terms of stability and synthetic flexibility. In the present case it made possible an investigation of the effect of acyl groups in a critical region of the molecule.

Our synthetic approach to the desired imidazo[1,2-a]pyridines envisioned incorporation of vinyl carboxamide followed by an alkylation with chloro or bromo ketones. The use of the one step procedure that we previously described for the generation of 2-aminoimidazo moiety from the corresponding 2chloropyridinium salts (or ylides) would allow a direct access to our target structures.?

To this end, compound $2{ }^{8}$ was subjected to the Horner-Emmons reaction with $\operatorname{diethyl}(\mathrm{N}$ methylcarbamoylmethyl)phosphonate, using KHMDS as a base in DMF, to give the key intermediate vinyl carboxamide 4 as 3:1 mixture of $E$ and $Z$ isomers. ${ }^{9}$ The desired $E$-isomer $4^{10}$ was obtained in its pure form after a column chromatography.<smiles>O=C(c1ccccc1)c1ccc(Cl)nc1</smiles>

2

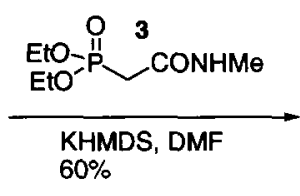

KHM
$60 \%$<smiles>CNC(=O)C=C(c1ccccc1)c1ccc(Cl)nc1</smiles><smiles>CNC(=O)C=C(c1ccccc1)c1ccc(Cl)nc1</smiles><smiles>[X]CC([R])=O</smiles>

5a, $R=M e, X=B r$

$5 b, R=P h, X=C l$

5c, $R=4-F-P h, X=C l$

5d, $R=t-B u, X=B r$<smiles>[R]C(=O)C[n+]1cc(C(=CC(=O)NC)c2ccccc2)ccc1Cl</smiles><smiles>[R]C(=O)C[n+]1cc(C(=CC(=O)NC)c2ccccc2)ccc1Cl</smiles>

$6 \mathbf{a}$<smiles>[R]C(=O)Cn1cc(/C(=C/C(=O)NC)c2ccccc2)ccc1=NC=N</smiles><smiles>[R]C(=O)c1c(N)nc2ccc(/C(=C/C(=O)O)c3ccccc3)cn12</smiles>

$$
\begin{aligned}
& \text { 1a, } R=\operatorname{Me}(50 \% \text { Yield }) \\
& 1 b, R=P h(40 \%) \\
& \text { 1c, } R=4-F-P h(38 \%) \\
& \text { 1d, } R=t-B u(30 \%)
\end{aligned}
$$

$\mathrm{H}_{2} \mathrm{NCN}, \mathrm{CH}_{3} \mathrm{CN}$

$\mathrm{K}_{2} \mathrm{CO}_{3}$ (1 eq. for 6b-d; 2eq. for 6a)

Scheme 1 
Reaction of 2-chloro-5-(1-phenyl-2- $N$-methylcarbamoylvinyl)pyridine $(E)$-4 with the commercially available chloroketone $\mathbf{5 b , c}$ or bromoketone $\mathbf{5 a , d}$, under refluxing acetonitrile in the presence of $\mathrm{NaI}$, afforded in three cases the corresponding heterobetaines $6 \mathrm{~b}(85 \%$ yield), $6 \mathrm{c}(67 \%)$ and 6d $(46 \%)$ and only in one case the pyridinium salt 6a $(60 \%)$. Interestingly the presence of $N$ methylcarbamoylvinyl function in this substrate facilitates the alkylation process and there was no need for the microwave assistance as in the examples that we have previously reported. ${ }^{7}$ Finally, our one-step procedure $^{7}$ for the generation of 2-aminoimidazo moiety was applied successfully for the completion of our target molecules. Thus, treatment of substrates $6 \mathrm{a}-\mathbf{d}$ with cyanamide in presence of $\mathrm{K}_{2} \mathrm{CO}_{3}$ in refluxing acetonitrile, furnished directly the corresponding 2-aminoimidazo[1,2-a]pyridines 1a-d. It is most likely that the cyanamide acts as a nucleophile that displaces the chlorine on pyridinium salt $6 \mathrm{a}$ or ylides $\mathbf{6 b - d}$ to form an intermediate (Scheme 1) that cyclizes under basic conditions. Importantly, in the case of ylides $6 \mathrm{~b}-\mathrm{d}$ only 1 eq. of $\mathrm{K}_{2} \mathrm{CO}_{3}$ was needed, while in the case of pyridinium salt $6 \mathrm{a}, 2 \mathrm{eq}$. of base were required for the complete conversion. This conversion is notable in that it affords the desired 2amino imidazo[1,2-a]pyridine derivatives in one-step, which is to our knowledge the shortest known method for the access to this type of nucleus.

The final imidazo[1,2-a]pyridines 1a-d were subjected to biological evaluation taking Enviroxime as a reference. Human rhinovirus- 14 was selected as the routine and initial virus for testing due to the amount of information known about this serotype. The plaque reduction assays (PRA) were run in order to determine the antiviral activity $\mathrm{IC}_{50}$ and the cytopathic effect assays (CPE/XTT) were performed as described previously ${ }^{11}$ in order to determine the general cellular toxicity $\mathrm{TC}_{50}$ (Table 1$)$.

Table 1. Anti-Rhinoviral Activity $\left(\mathrm{IC}_{50}\right)$ and Cellular Toxicity $\left(\mathrm{TC}_{50}\right)$ of Imidazopyridines 1a-d.

\begin{tabular}{ccccc}
\hline Compds & $\mathrm{R}$ & $\begin{array}{c}\mathrm{IC}_{50}(\mu \mathrm{g} / \mathrm{mL}) \\
\mathrm{PRA}^{\mathrm{a}}\end{array}$ & $\begin{array}{c}\mathrm{TC}_{50}(\mu \mathrm{g} / \mathrm{mL}) \\
\mathrm{CPE} / \mathrm{XTT}^{\mathrm{b}}\end{array}$ & $\begin{array}{c}\text { Dihed. Angle }^{\mathrm{c}} \\
(\mathrm{C} 2, \mathrm{C} 3, \mathrm{CO}, \mathrm{O})\end{array}$ \\
\hline 1a & $\mathrm{Me}$ & 2.48 & 22.8 & -1.7 \\
1b & $\mathrm{Ph}$ & 0.24 & 2.95 & 19.7 \\
1c & 4-F-Ph & 0.37 & 3.97 & 20.2 \\
1d & $t$-Bu & 0.17 & $>10$ & 45.2 \\
\hline
\end{tabular}

${ }^{a}$ Plaque reduction assay using HRV-14; Enviroxime used as reference $\left(\mathrm{IC}_{50}=0.045 \mu \mathrm{g} / \mathrm{mL}\right)$.

${ }^{\mathrm{b}} \mathrm{CPE} / \mathrm{XTT}$ assay using HRV-14. ${ }^{\mathrm{c}}$ Dihedral angles, calculated with AM1 hamiltonian.

An acetyl group at 3-position afforded a compound with moderate antiviral activity. Interestingly $t$-butylacetyl at the same position provided a compound with an $\mathrm{IC}_{50}(\mu \mathrm{g} / \mathrm{mL})$ of 0.17 in PRA assay, 15 fold more active than the methyl partner. A benzoyl substituent at $\mathrm{C}(3)$ also provided a potent compound. A substitutent in para-position such as fluorine on the $\mathrm{C}(3)$ aryl was well-tolerated, providing a compound that maintained the activity. The biological data suggested that the antiviral activity is depending on the size of the group at C-3 and increases in the order methyl<aryl< $t$-butyl. However, the presence of an oxygen $(\mathrm{C}=\mathrm{O})$ that may participate in internal hydrogen bonding with the amine hydrogen 
does not seem to be critical to anti-rhinoviral activity as in the case of Enviroxime, ${ }^{2}$ since the activity observed in the examples $\mathbf{1 b}$ and $\mathbf{1 c}$ is in the same order as that exhibited by their aryl partners. ${ }^{6}$

In order to help understanding the role of the size of the group at C-3 on the activity, we carried out semi-empirical calculations. Compound 1a-d were studied using AM1 hamiltonian. The conformational profiles calculated for each structure exhibit minima that differ mostly in the dihedral angle around the carbonyl at $\mathrm{C}-3(\mathrm{C} 2, \mathrm{C} 3, \mathrm{CO}, \mathrm{O})$. The geometrical feature of this angle seems to correlate with the activity in this class of compounds. Higher dihedral angle in $1 \mathrm{~d}\left(45^{\circ}\right)$ afforded a compound with potent antirhinoviral activity. On the other hand compound 1a with very small dihedral angle $\left(-1.7^{\circ}\right)$ didn't show significant activity.

Finally, compounds 1a-d were evaluated in a cytopathic effect assay in order to determine the general cellular toxicity $\mathrm{TC}_{50}$. Compound $1 \mathrm{~d}$ seems to have quite high therapeutic index (ratio of $\mathrm{TC}_{50}$ over $\mathrm{IC}_{50}$ is higher than 60 ). In general no apparent cellular toxicity was observed in this series of compounds.

In summary, we have described an efficient approach to the synthesis of acyl substituted imidazo[1,2-a]pyridines, structurally related to Enviroxime. This study demonstrated that imidazopyridine nucleus not only maintains the anti-rhinoviral activity found in benzimidazole but also admits groups that are not tolerated in benzimidazoles. In the present case it allows to investigate the effect of acyl groups in a critical region of the molecule. Compounds $1 b, 1 c$ and $1 d$ exhibited strong anti-rhinoviral activity and no apparent cellular toxicity was found.

Acknowledgements. This research was supported by a CDTI program (Plan concertado 96/0036) and the Spanish Farma III programme (Ministerio de Industria y Ministerio de Sanidad). We are also grateful to the Lilly Rhinovirus Action Group for their advice and interest in this work.

\section{References and Notes}

(1) (a) Wikel, J. H.; Paget, C. J.; DeLong, D. C.; Nelson, J. D.; Wu, C. Y. E.; Paschal, J. W.; Dinner, A.; Templeton, R. J.; Chaney, M. O.; Jones, N. D.; Chamberlin, J. W. J. Med. Chem. 1980, 23, 368-372. (b) DeLong, D. C. In Microbiology, Leive, L., Schlessinger, D, C., Ed.; American Society for Microbiology: Washington, D. C., 1984; pp 431-434. (c) DeLong, D. C.; Reed, S. E. J. Infect. Dis. 1980, 141, 87.

(2) (a) Victor, F.; Loncharich, R.; Tang, J.; Spitzer, A. W. J. Med. Chem. 1997, 40, 3478. (b) Victor, F.; Brown, T. J.; Campanale, K.; Heinz, B. A.; Shipley, L. A.; Su, K. S.; Tang, J.; Vance, L. M.; Spitzer, W. A. J. Med. Chem. 1997, 40, 1511.

(3) Heinz, B. A.; Vance, L. M. J. Virol. 1995, 69, 4189. (b) Heinz, B. A.; Vance, L. M. J. Virol. 1996, $70,4854$.

(4) (a) Phillpotts, R. J.; Delong, D. C.; Wallace, J.; Jones, R. W.; Reed, S.E.; Tyrrell, D. A. Rhinovirus Infection in Man. Lancet 1981, 1/8234, 1342-1344. (b) Miller, F. D.; Monto, A. S.; DeLong, D. C.; Exelby, A.; Bryan, E. R.; Srivastava, S. Antimicrob. Agents Chemother. 1985, 27, 102.

(5) Tebbe, M. J.; Spitzer, W. A.; Victor, F.; Miller, S. C.; Lee, C. C.; Sattelberg, T. R.; McKinney, Sr. E.; Tang, J. C. J. Med. Chem. 1997, 40, 3937.

(6) Hamdouchi, C.; de Blas, J.; del Prado, M.; Gruber, J.; Heinz, B. A.; Vance, L. J. Med. Chem. 1999, 42, 50.

(7) Vega, J. A.; Vaquero, J. J.; Alvarez-Builla, J.; Ezquerra, J.; Hamdouchi, C. Tetrahedron, 1999, 552317.

(8) Compound 2 was prepared by Friedel-Crafts acylation of benzene with 6-chloronicotinyl chloride.

(9) The Horner-Emmons reaction of compound 2 with diethyl(N-methylcarbamoylmethyl)phosphonate 3 was studied in different bases and solvents and the best results were achieved with KHMDS in DMF.

(10) The geometry of compound $(\boldsymbol{E})-4$ was established by NOE experiments

(11) Tang, J.; Colacino, J. M.; Larsen, S. H.; Spitzer, W. Antiviral Res. 1990, 13, 313. 